\title{
中国洪水预报系统新安江模型在蚂蚁河延寿水文站洪水预报 中的应用
}

\author{
赵忠武 邢卫江 狄方洪 \\ 黑龙江省哈尔滨水文局
}

DOI:10.32629/hwr.v3i2.1878

[摘 要] 延寿水文站系松花江一级支流蚂蚁河重要控制站,位于延寿县延寿镇。文章通过延寿站新安江模型洪水预报方案的 率定及检验, 确定此方案为该站重要的洪水预报方法,为防汛抗洪提供水文预报数据。由参数率定可知, 洪水过程拟合效果较好, 水量基本平衡,各参数符合该地区的洪水特性,根据确定性系数 0.907 评定该预报方案为甲级。

[关键词] 水文站; 模型; 洪水预报; 误差

\section{1 概况}

雨量站选用: 经雨量资料分析, 延寿水文站以上区间共 有尚志、延寿、黑龙宫水库、杨树、得好村、国庆村、莲河 村、万发村、兴隆村 9 站雨量资料。雨量摘录资料, 具备编 制洪水预报方案的要求。资料系列详见表 1 。

水文站的选用: 尚志水文站、杨树水文站资料经过整编, 能满足编制洪水预报方案要求。尚志水文站 2002 年建站, 建站以来最大流量为 $711 \mathrm{~m}^{3} / \mathrm{s}$, 杨树水文站 1957 年建站, 建站 以来最大流量为 $788 \mathrm{~m}^{3} / \mathrm{s}$, 根据雨量资料系列, 流量资料选用 2003 年、 2005 年、 2006 年、 2007 年、 2008 年、 2009 年、 2010 年、 2012 年、 2013 年、 2014 年分析, 资料审查情况详 见表 2 , 延寿站水位流量关系见表 3 。

蒸发资料选用: 选用延寿水文站蒸发资料。详见表 1-3。 表 1 延寿水文站预报断面选用资料及年限情况表

\begin{tabular}{|c|c|c|c|c|}
\hline 站码 & 站名 & $\begin{array}{c}\text { 资料 } \\
\text { 类型 }\end{array}$ & $\begin{array}{c}\text { 建站 } \\
\text { 年份 }\end{array}$ & 起止年份 \\
\hline 11007650 & 尚志 & $\begin{array}{c}\text { 河道 } \\
\text { 流量 }\end{array}$ & 2002 & $2003 \sim 2014$ (实时洪摘资料齐全) \\
\hline 11008110 & 杨树 & $\begin{array}{c}\text { 河道 } \\
\text { 流量 }\end{array}$ & 1957 & $1960 \sim 2014$ (历史雨摘资料齐全) \\
\hline 11007700 & 延寿 & $\begin{array}{c}\text { 河道 } \\
\text { 流量 }\end{array}$ & 1950 & $1955 \sim 2014$ (历史洪摘资料齐全) \\
\hline 11007940 & $\begin{array}{c}\text { 黑龙宫 } \\
\text { 水库 }\end{array}$ & 雨量 & 1957 & $1958 \sim 2012$ (历史雨摘资料齐全) \\
\hline 11044702 & 得好村 & 雨量 & 2008 & $2008 \sim 2014$ (实时雨摘资料齐全) \\
\hline 11044704 & 国庆村 & 雨量 & 2008 & $2008 \sim 2014$ (实时雨摘资料齐全) \\
\hline 11044706 & 莲河村 & 雨量 & 2008 & $2008 \sim 2014$ (实时雨摘资料齐全) \\
\hline 11044708 & 万发村 & 雨量 & 2008 & $2008 \sim 2014$ (实时雨摘资料齐全) \\
\hline 11044900 & 兴隆村 & 雨量 & 1976 & $2005 \sim 2014$ (实时雨摘资料齐全) \\
\hline
\end{tabular}

表 2 延寿水文站资料审查表

\begin{tabular}{|l|l|l|l|l|}
\hline 序号 & 年 份 & 洪峰流量 & 发生时间 & 资料情况 \\
\hline 1 & 2003 & 234 & $2003-7-27 \quad 8$ & 洪摘、雨摘齐全 \\
\hline 2 & 2005 & 395 & $2005-8-14 \quad 2$ & 洪摘、雨摘齐全 \\
\hline 3 & 2006 & 287 & $2006-8-13 \quad 18$ & 洪摘、雨摘齐全 \\
\hline 4 & 2007 & 65.2 & $2007-5-27 \quad 8$ & 洪摘、雨摘齐全 \\
\hline 5 & 2008 & 106 & $2008-7-20 \quad 3$ & 洪摘、雨摘齐全 \\
\hline 6 & 2009 & 505 & $2009-7-23 \quad 2$ & 洪摘、雨摘齐全 \\
\hline 7 & 2010 & 366 & $2010-5-7 \quad 5$ & 洪摘、雨摘齐全 \\
\hline 8 & 2012 & 336 & $2012-7-31 \quad 3$ & 洪摘、雨摘齐全 \\
\hline 9 & 2013 & 763 & $2013-7-5 \quad 17$ & 洪摘、雨摘齐全 \\
\hline 10 & 2014 & 202 & $2014-5-178$ & 洪摘、雨摘齐全 \\
\hline
\end{tabular}

表 3 蒸发站月值

\begin{tabular}{|l|l|l|l|l|l|l|l|l|l|l|l|l|}
\hline 月份 & 1 & 2 & 3 & 4 & 5 & 6 & 7 & 8 & 9 & 10 & 11 & 12 \\
\hline $\begin{array}{c}\text { 蒸 发 } \\
(\mathrm{mm})\end{array}$ & 7.7 & 24.8 & 44.2 & 104.1 & 147.4 & 157.4 & 152.2 & 135.7 & 78.8 & 53.9 & 11.2 & 5.6 \\
\hline
\end{tabular}

\section{2 新安江模型预报方案}

2.1 预报方案构建

预报方案设置 3 个方案输入：尚志水文站 (11007650)、 杨树 (11008110) 和 $11007700 \mathrm{~A}$ (延寿集水面积 $5627 \mathrm{~km}^{2}$, 尚志 集水面积 $2498 \mathrm{~km}^{2}$, 杨树集水面积 $975 \mathrm{~km}^{2}, 3$ 站控制面积 $\left.2154 \mathrm{~km}^{2}\right)$ 。尚志至延寿用马法, 杨树至延寿用马法演算, 区间 输入采用蓄满产流模型 (SMS_3) 和滞后演算模型 (LAG_3) ; 雨 量站控制权重采用泰森多边形法。方案计算时段为 1 小时, 方案输出类型为流量。其结构图如下。

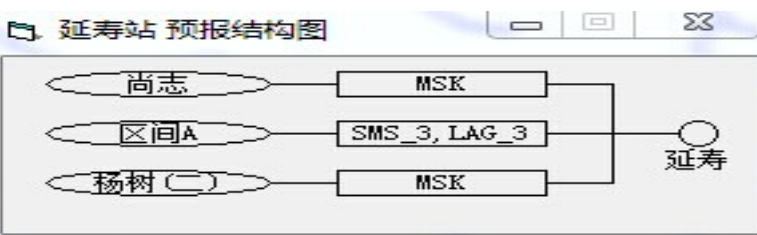

图 1 延寿站预报结构图

\section{2 方案定义及属性}

(1) 方案定义

模型：马斯京根河道分段连续演算模型 (MSK) 、、新安江 三水源蓄满产流、滞后演算;

方案输入：尚志水文站 (11007650)、杨树 (11008110) 和区间 $11007700 \mathrm{~A}$ 包括黑龙宫水库、得好村、国庆村、莲河 村、万发村、兴隆村雨量站时段降雨过程;

方案输出：延寿站时段流量过程。

(2) 方案属性

预报站码： 11007700 (延寿)；

时段长度: 1 小时;

预见期: 36 个时段;

预热期：30 天; 
输出类型: 河道流量;

输入个数: 3 个;

输入类型: 2 个河道输入和 1 个流域输入。

2.3 圈化流域边界

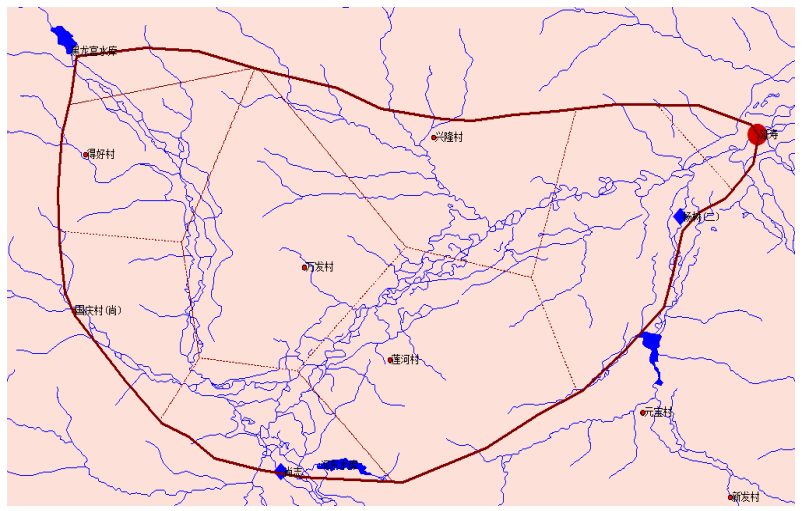

图 2 延寿站流域边界示意图

2.4 参数率定结果

(1) 目标函数统计见下表:

表 4 延寿站率定目标函数值统计表

\begin{tabular}{|l|l|}
\hline 方案名称 & 方案一 \\
\hline 确定性系数 & 0.907 \\
\hline
\end{tabular}

(2) 参数率定结果

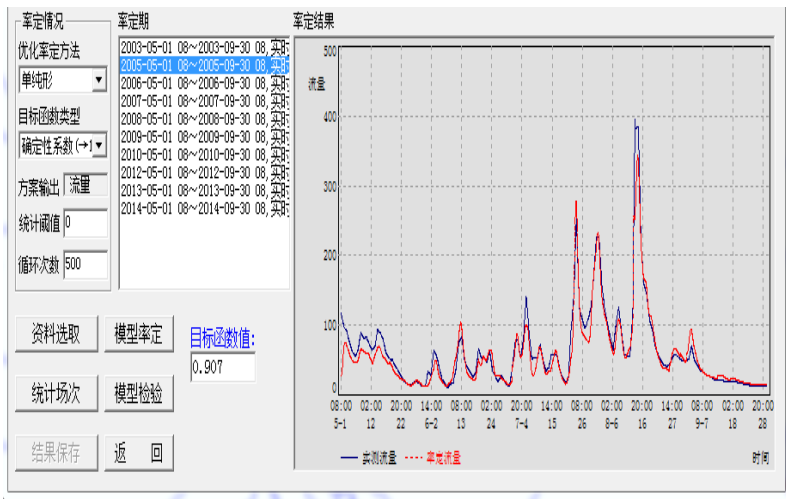

图 3 2005-05-1 至 2005-09-30 率定结果图

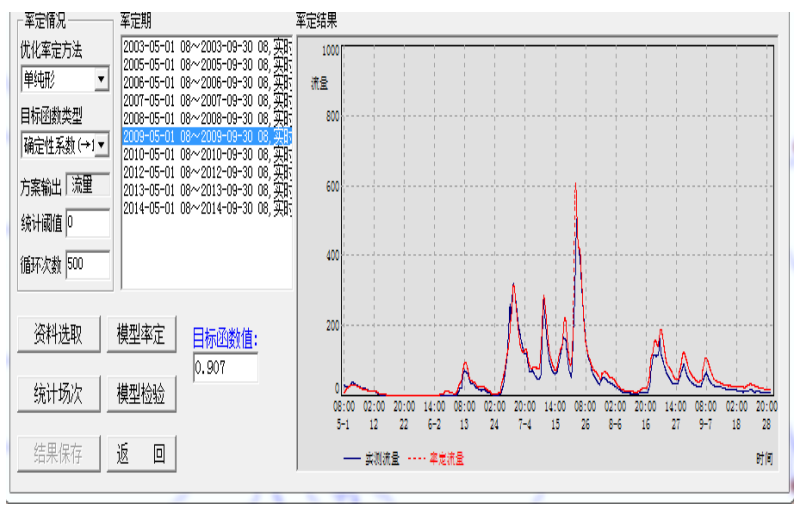

图 4 2009-05-01 至 2009-09-30 率定结果图
2.5 模型参数

(1) 马斯京根河道分段连续演算模型 (MSK) 的参数

11007700 11007650MSK

PARAMETER

\&PARA TABLE

$X=-1.000$

$\mathrm{KK}=1$

$\mathrm{MP}=18$

/

$11007700 \quad 11008110$ MSK

PARAMETER

\&PARA TABLE

$X=-0.080$

$\mathrm{KK}=1$

$\mathrm{MP}=0$

/

(2) 三水源蓄满产流模型 (SMS_3) 的参数

11007700 110077006ASMS_3

PARAMETER

\&PARA_TABLE

$W M=120.000$

$\mathrm{WUMx}=0.200$

$W L M x=0.600$

$\mathrm{K}=0.696$

$\mathrm{B}=0.350$

$\mathrm{C}=0.100$

$\mathrm{IM}=0.020$

$\mathrm{SM}=80.606$

$\mathrm{EX}=1.500$

$K G=0.462$

$\mathrm{KI}=0.437$

ES=7. 7 24. 8 44. 2 104. 1 147. 4 157. 4 152. 2135.778 .8 53.911 .25 .6

(3) 三水源滞后演算汇流模型 (LAG_3) 的参数

11007700 110077006ALAG_3

PARAMETER

\&PARA TABLE

$\mathrm{F}=2154$

$\mathrm{CI}=0.478$

$\mathrm{CG}=0.990$

$\mathrm{CS}=0.953$

$\mathrm{LAG}=11.000$

$\mathrm{X}=-0.032$

$\mathrm{KK}=1$

$\mathrm{MP}=0.000$ 
各项产流参数的意义:

$K$ : 流域蒸散发折算系数。实测的蒸发量 (由蒸发皿得到)

乘上 $K$ 就是流域蒸散发能力。

WM (WUM、WLM、WDM) : 流域平均的蓄水容量, 以 $\mathrm{mm}$ 计。 它是反映流域干旱程度的指标, 它分成上中下三层, 相应的 容量系数是 WUM、WLM 和 WDM。

$\mathrm{C}$ : 深层蒸发折算系数。

IMP 是不透水面积占全流域面积的比例。一般都只取值 0.01 或 0.02 。

$\mathrm{B}$ 是流域蓄水容量曲线的方次, 它反映流域面上蓄水容 量分布的不均匀性。在很大程度上, 它取决于流域地形地貌 地质情况的均一程度。B 的取值范围一般在 $0.15 \sim 0.3$, 或更 大些。

$K G$ 和 $K I$ 。KG、KI 分别是自由水蓄水库的地下水出流系 数及壤中流出流系数, 对应着自由水蓄水孔的两个出流孔, 是并联结构。

SM: 流域平均的自由水蓄水容量。这是个比较重要的参 数, 决定了地表径流与另两种径流在量上的比例关系, 与洪 峰的形状、高低有较大关系。

$\mathrm{EX}$ : 自由水蓄水容量曲线的指数, 表示自由水容量在流 域面上分布的不均匀性, 与流域蓄水容量曲线中的 B 相仿。 EX 的影响不太大,一般流域取 1.5 即可。

各项汇流参数的意义:

$\mathrm{CI}$ 。深层壤中流的消退系数。
$\mathrm{CG}$ 。地下径流消退系数。

$\mathrm{CS}$ 和 LAG：决定于河网地貌。CS 为河网蓄水消退系数, 反映洪水过程坦化的程度。LAG 为滞后时段数, 反映洪水过 程平移程度。

$\mathrm{X}$ 和 $\mathrm{KK}$ 。马斯京根法分段连续演算的两个参数。

MP。马斯京根法分段连续演算的河段数。

分段连续演算模型 (MSK) 的参数的意义:

$\mathrm{x}$ ：子河段流量比重因素，反映河槽调蓄能力的一个指 标。一般是随着河道比降逐渐平坦, 洪水波变形量大, 河槽调 蓄作用增强, $\mathrm{x}$ 值减小。

$\mathrm{K}$ : 子河段蓄量常数。一般取计算时间长。

MP: 子河段数。

\section{3 方案评定}

由上述参数率定结果可知, 洪水过程拟合效果较好, 水 量基本平衡, 各参数符合该地区的洪水特性, 根据确定性系 数 0.907 评定该预报方案为甲级。

对 2009 年 -2014 年进行检验, 确定性系数为 0.888 。

\section{[参考文献]}

[1]章四龙.中国洪水预报系统设计建设研究 [J]. 水 文,2002(02):32-34.

[2]包为民.水文预报[M].中国水利水电出版社,2009(05):136.

[3]中国国家标准化管理委员会.水文情报预报规 范:(GBT22482-28)[S].2008-11-04. 